\title{
Chapter 12 \\ Japan's Comprehensive and Continual Support Package for the Creation of Scientific Climate Policies in Asia
}

\author{
Tomoko Ishikawa and Shuzo Nishioka
}

\begin{abstract}
The response to climate change is a matter of increasing urgency, and from 2020, every nation will be required to reduce its GHGs. The unified reduction policies of the central governments of each country form the core of reduction policy implementation. Actual reductions are planned and implemented for each region and sector. As climate policies are strongly related to the development strategies and energy policies of each country, it is thus necessary for each country to independently mobilise knowledge to formulate strategies and policies based on domestic natural and developmental conditions.
\end{abstract}

The response to climate change has brought about a major turning point in modern civilisation, which was founded, and yet is still heavily dependent on fossil fuel energy. As Asian countries are currently in a period of strong growth, Asia as a whole must set a course towards low-carbon development that differs from the paths taken to date by developed industrialised countries. Science-based initiatives are indispensable to the formulation of climate policies, and in order for individual countries to frame policies and maintain ownership of them, scientific bases will, respectively, need to be created by each country.

From 2020, part of all-country participation in climate change mitigation entails INDCs (Intended Nationally Determined Contributions) be formulated. It is here that the achievements of a series of scientific cooperation projects promoted in the Asian region by the Government of Japan, in particular the Japanese Ministry of the Environment, can fully be appreciated.

Reducing GHG via scientific policymaking involves following the sequence of reduction target setting, reduction policy design, policy implementation, continuation and feedback (see Fig. 12.2). In order to carry this out, it is necessary to (1) ascertain GHG emission volumes for all processes (GHG inventories); (2) establish approaches to create unified climate policies for central and local governments (technologies, energy and GHG policy integrated assessment model, IAM); and (3) develop mechanisms to foster related research communities and strengthen

T. Ishikawa $(\varangle) \cdot S$. Nishioka

Institute for Global Environmental Strategies (IGES), Kanagawa, Japan

e-mail: t-ishikawa@iges.or.jp 
contributions therefrom to policy formulation (e.g. via strategic research programmes, fora for dialogue on policy and science).

In light of the growing importance of Asia in terms of global climate policy, the Government of Japan, together with other Asian countries, has promoted the creation of such scientific bases since the 1980s. These efforts have significantly assisted in policy formulation, including INDCs, in Asian nations. Further, the Low Carbon Asia Research Network (LoCARNet), comprising researchers directly engaged in climate policymaking processes in each country, was launched in 2012 in view of the rise in urgency of climate policy. LoCARNet has since organised relevant research communities based on ownership in each country to engage in the challenge of low-carbon development in Asia by facilitating knowledge sharing and cooperation throughout the Asian region.

Section 12.1 of this report describes the cooperation between Government of Japan and other Asian countries. Section 12.2 introduces in particular the activities of LoCARNet towards building research communities to promote concrete actions from 2020 as good practices to be disseminated throughout the world.

Keywords LoCARNet - Ministry of Environment of Japan - Scientific policymaking - Integrated assessment model - PDCA • Regional South-SouthNorth Collaboration

\section{Key Message to Policy Makers}

- Asia holds the key to global climate stability.

- Science-based initiatives are indispensable to the formulation of climate policies.

- Government of Japan has promoted the creation of scientific bases in Asia since the 1980s, which has aided in formulating policy, including INDCs in Asian nations.

- LoCARNet has organised relevant research communities based on ownership in each country, to engage in the challenge of low-carbon development in Asia.

It is hoped Asia will take lead the way in a global transition to low-carbon societies, by establishing and implementing science-based policies. 


\subsection{Japan's Strategies to Support Scientific Climate Policymaking in Asia}

\subsubsection{Scope of Scientific Climate Policy}

\subsubsection{Scientific Context for Climate Policy}

Based on observation results and model predictions, in the Fifth Assessment Report of the IPCC (AR5), Working Group I deemed that cumulative anthropogenic GHG emissions and global temperature increase have a proportional relationship (Fig. 12.1) (IPCC 2013: Summary for Policymakers. In Climate Change 2013: The Physical Science basis, p. 28). Carbon cycle research has shown that almost half of anthropogenic GHGs emitted are not absorbed and remain in the atmosphere. As the atmospheric lifetime of $\mathrm{CO}_{2}$, which accounts for the majority of GHG, is thought to be more than 100 years, as long as emissions continue, the amount of $\mathrm{CO}_{2}$ remaining in the atmosphere can only continue to rise. According to global warming theory, a rise in atmospheric concentration of GHGs directly results in a rise in temperature; therefore, as long as human-induced GHG emissions continue, so will the rise in global atmospheric temperature.

It is precisely because of the proportional relationship described above that we now face a critical issue-which is that whatever the temperature rise compared with the pre-industrial figure is, human-induced emissions must be brought to zero when such temperature is reached in order to stabilise climate. Ultimately, this means we must create a zero-emission world.

Linear relation between cumulative GHG emissions \& temperature rise

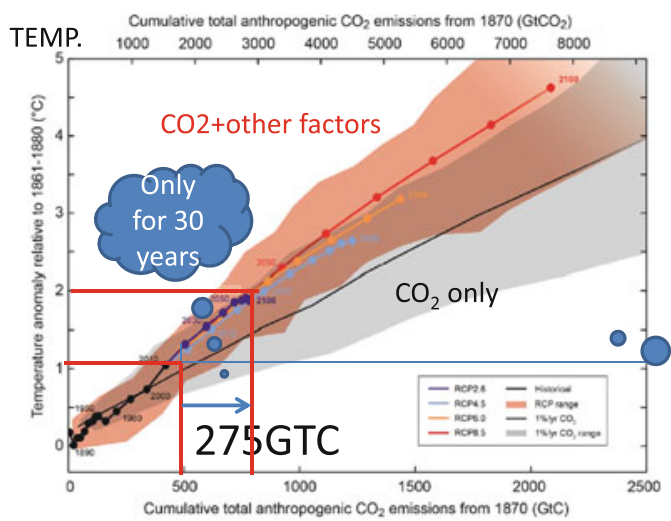

$\cdot 2^{\circ} \mathrm{C} \Rightarrow 790 \mathrm{GtC}$

- $515 \mathrm{GtC}$ emitted already - only 275 GtC remaining $\cdot 2013$ emissions $=9.9 \mathrm{GtC}$

Cumulative total anthropogenic CO2 emissions from 1870 (GtCO2)

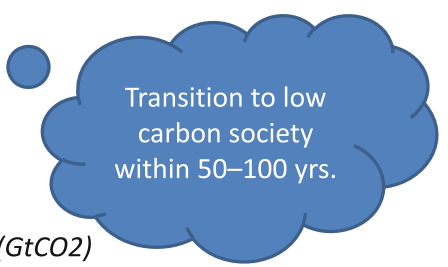

(IPCC AR4 and Emori, NIES)

Fig. 12.1 Zero emission is the ultimate solution to stabilise climate 
Agreements were reached at the G8 summit and UNFCCC COP16 (Cancun Agreements) of 2010 on a policy objective to limit the temperature rise to two degrees over pre-industrial levels, based on Article 2, 'Objective', of the Framework Convention on Climate Change, which calls for 'a level that would prevent dangerous anthropogenic interference with the climate system'. If the cumulative emissions corresponding to $2{ }^{\circ} \mathrm{C}$ are read from the IPCC/AR5 proportional graph, from which the cumulative anthropogenic emissions already released to date are subtracted, the amount of emissions permissible for a $2{ }^{\circ} \mathrm{C}$ increase is no more than around 30 years' worth of global emissions based on the emissions for 2010. Under these circumstances, the mission of the current generation should therefore be to be as frugal with this limited allowance as possible and, while evolving through the required stage of low-carbon society before this 'emissions budget' is used up (likely 50 to 100 years), also aim to create a zero-emission society for the whole world. The IPCC Working Group III has indicated the feasible emission pathway, namely, one that would reduce current global emissions (40 billion tonnes $\mathrm{CO}_{2}$ equivalent) to half (20 billion) by 2050 (IPCC 2014: Summary for Policymakers. Working group III: Mitigation of Climate Change, p. 11).

If this 20 billion tonne allowance is distributed according to the projected population in 2050 of 10 billion, per capita $\mathrm{CO}_{2}$ emissions are calculated to be about 2 tonnes. However, the reality is that per capita emissions have already topped 17 tonnes in the United States, 9 in Japan, 5.5 in China, 3 in Thailand, 1.6 in Indonesia and 1.4 in India. These figures reveal that almost all of these countries need to draw up policies to reduce GHG emissions. This represents a major transition challenge for developed countries, which were founded on, and at the same time are struggling to be free from lock-in of highly energy-consuming technologies, as they will need to overhaul their social infrastructure to one based on low-carbon society. Conversely, the major challenge for developing countries is their need to discover new, low-carbon development pathways that leapfrog over those utilised by developed countries to date.

\subsubsection{Scope and Processes of Policy and Scientific Basis}

What kinds of policies are needed when confronted with a major transition to a low-carbon world as described above? As energy policy is at the core of GHG emission reduction policy, it goes without saying that controls on energy consumption and a change in the structure of primary energy supply are required. However, policy cannot stop there-transitions are required in all sectors related to consumption and supply, including cities, land use, residential, transport and industry. The various sectors that must be covered by climate policy are indeed wide-ranging.

Formulation of long-term climate mitigation policies is carried out with the GHG emission reduction as an axis following the procedures shown in the middle of the figure below (Fig. 12.2): target setting, policy formulation, policy evaluation, monitoring of implementation results and feedback on the policy overall. 


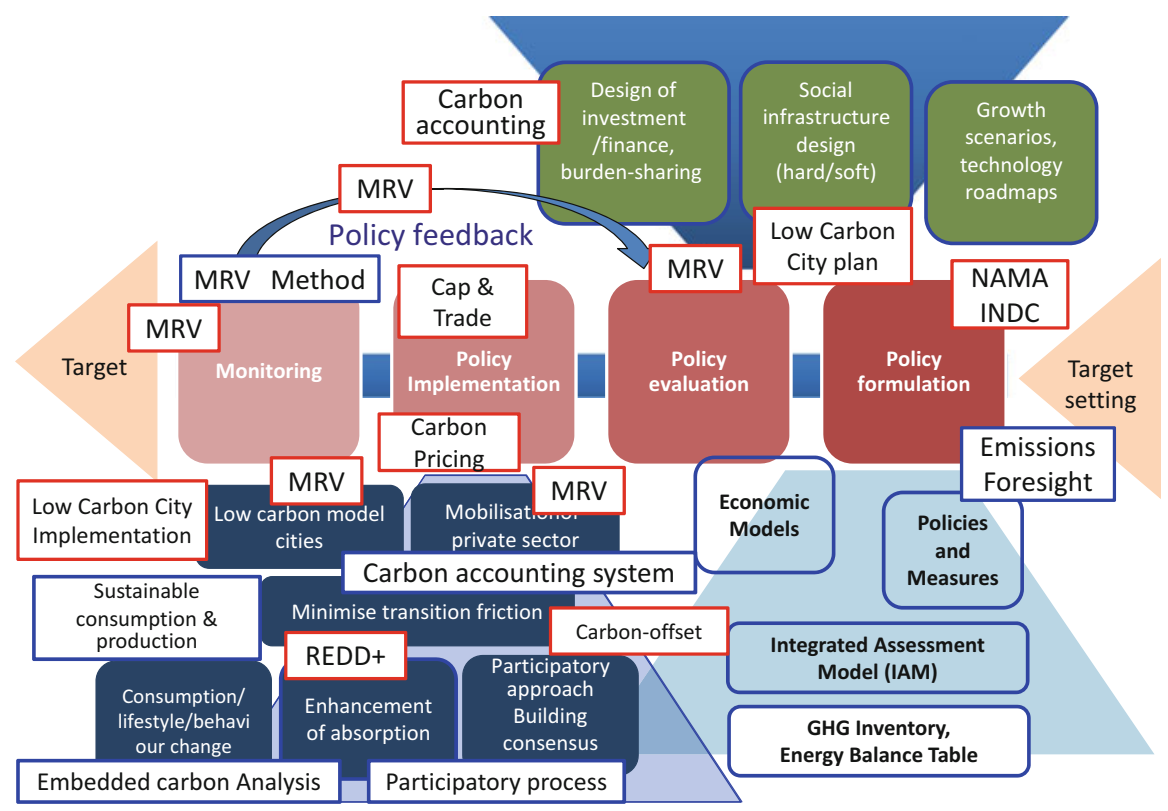

Fig. 12.2 Climate policy sequence and scientific support tools

Reduction targets are often decided a priori, as international agreements of the UNFCCC (e.g. reduction targets of the Kyoto Protocol) or as decisions by top management (e.g. the 26/41\% reductions of former President Yudhoyono of Indonesia). Leading up to these decisions are deliberations on approximate reduction outlooks and setting of rough targets based on such. When the world shifts its gaze in the direction of low-carbon society, as discussed above, the 2 tonne $\mathrm{CO}_{2}$ per capita by 2050 figure will constitute a solid basis for reduction targets.

Subsequently, emission reduction scenarios based on reduction targets are needed. Based on economic growth rates and demographics, the necessary amount of services by sector for continuation of conventional policy (BaU: Business as Usual) and the energy needed to enable these services are calculated. These figures are then cross-referenced with the appropriate primary energy utilising an energy balance table, and then by multiplying GHG emissions per unit of primary energy, the GHG emissions for the entire nation can be calculated. Determining volumes of various activities mainly uses statistical data, and if the amount of energy per unit of activity and the amount of GHG generated per unit of energy are known, GHG emissions can be estimated. In sum, this series of estimations, termed inventory computation', is the bedrock for science-based climate policy.

These consolidated inventories as described above are made for each sector. In order to maintain consistency amongst sectors and create an integrated policy scenario, the Integrated Assessment Model (IAM) is indispensable. Included in this model group are the energy technology list and the GHG emission reduction 
cost curve covering all technologies, allowing for calculation of additional investment amounts for the entirety of reduction policies and overall costs.

A range of measures are available to bring the $\mathrm{BaU}$ emissions calculated in this matter closer to the reduction target amount, including regulatory methods such as establishing emission caps by sector and economic methods, including a carbon tax. With the application of such policy instruments, the system of reduction policy is determined (see Fig. 12.2, bottom right). The resulting investment cost in the necessary infrastructure based on the overall reduction plan can be estimated (see Fig. 12.2, top right).

These measures are then evaluated according to their impact on long-term economic growth via CGE (Computable General Equilibrium) modelling, and efforts are made to coordinate them with higher level plans.

Measures to implement policies are entrusted to the parties involved in actual reductions (stakeholders), such as municipal and local governments, industries and citizens. Reduction measures are advanced in respect of actual situations; local governments execute them via city planning and administration, and rural villages do so through forest and land-use plans. Likewise, reform in industrial structure, resource efficiency in manufacturing and distribution in the industrial sector and energy conservation measures for offices and households take place. Measures in civil society include rational consumption-consumption based on maximised utility or benefit of products or services.

The PDCA (plan, do, check and action) assessment cycle is applied to the whole process; results of actions by each stakeholder group are consolidated periodically to undergo MRV (measurement, reporting and verification), whereby feedback is given on reinforcement of measures and changes to plans. Through PDCA, inventories and integrated assessment models used in the early stages of planning are effectively utilised as criteria to determine efficacy.

The above illustrates how substantial the scientific base is required to be for GHG reduction policy development. This base includes GHG inventories, policy formation based on integrated assessment models, economic assessment methods for policy, knowledge on policy formation and infrastructure building at the city level, calculation of resource efficiency by Life Cycle Assessment (LCA) methods and analysis of public behaviour. Further, as geographical, economic, resource and political factors vary across the region, so do the required scientific bases; therefore, each and every country needs to create domestic climate policies by fostering domestic research communities in order to realise scientific bases in accordance with domestic environments.

According to IPCC AR5, climate change is already progressing, and its impacts are evident around the world. Some countries have already been affected and have initiated adaptation activities. This makes the need to share scientific knowledge all the more important, not only in terms of mitigation but also adaptation. 


\subsubsection{Japan's Support for Climate Policies in Asia}

\subsubsection{Japan's Policy on Asian Cooperation}

In the Business as Usual (BaU) case, Asia is expected to account for half the world's economy, energy consumption and GHG emissions by the year 2050, thus the region holds the key to global climate policy in both aspects of GHG emission reduction and adaptation.

Japan, with its strong ties to neighbouring countries in Asia, both geographically, culturally, historically and economically, has since the 1980 s actively and continuously carried out initiatives in knowledge sharing to form scientific bases for climate change policy formulation. These efforts have already born fruit in Asia's developing countries and in the national communications and Biennial Update Reports (BUR) submitted to the UNFCCC. A strong foundation has also been laid for preparation of Nationally Appropriate Mitigation Actions (NAMA) and Intended Nationally Determined Contributions (INDCs), which are to start in 2015.

Japan's stance on climate change can be summed up in the following five principles: (1) adherence to international polluter pays principle (PPP), upholding Japan's responsibility; (2) active contribution as Environmental Nation, contributions that capitalise on Japan's capabilities in environmental protection; (3) full respect for partner's autonomy, support for self-reliance and autonomous environmental management of other countries; (4) contribution to global environmental diplomacy, exercising leadership in the environmental arena; and (5) positive facilitation of international agreements, preparing frameworks for international policy agreements.

The above five principles for action were discussed in the COSMO Plan (Nishioka, S., 1990: Policy scientific insight required for responding to Global Warming, Environmental Research Quarterly No. 77, January 1990, 14-20 (in Japanese)) in early 1990 (Comprehensive Strategies for Moderating Global Warming plan). Likewise, cooperation with other Asian nations on climate policy and support for policy formulation based on individual respective country ownership are also part of Japan's basic stance.

Japan's cooperation is based on forward thinking and long-term capacity building through sharing of scientific knowledge and world affairs, preparation of inventories, support for policy formulation and human resource development in science and policy. To such end, Japan believes countries in Asia should not rely on foreign consulting bodies and instead take ownership of policy formulation, based on the conviction that this will lead to enduring low-carbon development in Asia. This support from Japan has been acknowledged by Asian nations to date and has bestowed bonds of trust. 


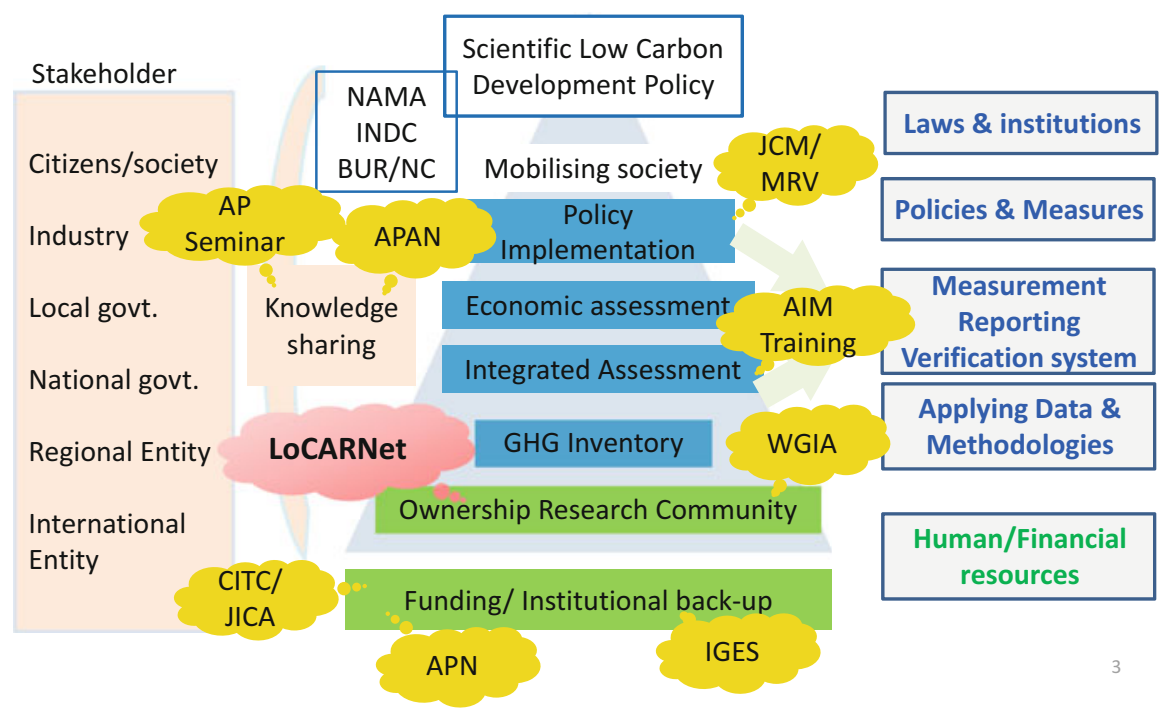

Fig. 12.3 Elements supporting scientific low-carbon development policy and Japanese collaboration with Asian countries

\subsubsection{Support for Comprehensive, Continual and Systematic Creation of Science-Based Policies}

The Ministry of the Environment of Japan has maintained, without interruption, its support for systematic science-based policy formulation in the Asian region, embracing all fields related to climate change (Fig. 12.3) (Table 12.1).

Climate change first caught the attention of science in the late 1970s, and in 1988, the IPCC was formed to evaluate its scientific aspects. In 1989, the Government of Japan held the 'Tokyo Conference on the Global Environment', which brought together experts from around the world to deliberate on how Japan would contribute to preserving the global environment and, in particular, how it could contribute to the climate change issue. While this event was over two decades ago, strong growth in Asia had already been anticipated at the time. Japan, with its strong ties in Asia, thus set out to form a system of technological and scientific cooperation based on the symbiotic viewpoint of mutual benefit.

Shared Recognition of Global Trends in Science and Policy Based on the fact that climate change is caused by human interference with nature, responses must begin by firstly deciphering what is happening in the natural environment and then sharing this insight - scientific knowledge. This is just what Japan did, as immediately after the release of the first IPCC report in 1990, GoJ launched the 'AsiaPacific Seminar on Climate Change' for knowledge-sharing amongst Asian nations. The meeting, which convened environment policymakers from several Asian countries, was jointly sponsored by UNEP/UNCRD and included Chairman Bolin of the IPCC, as well as Chairman Izrael and Vice-Chairman Hashimoto of Working 


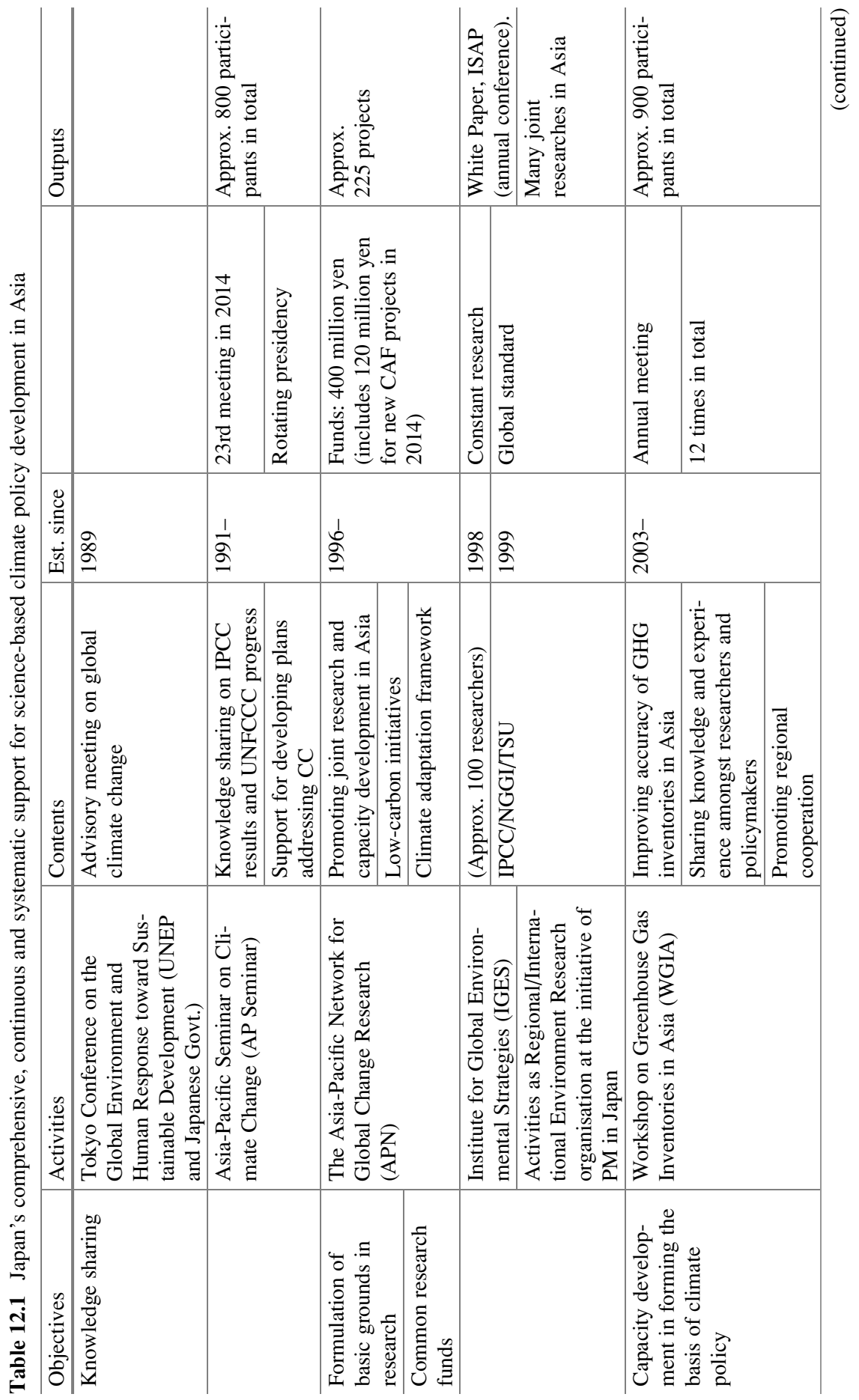




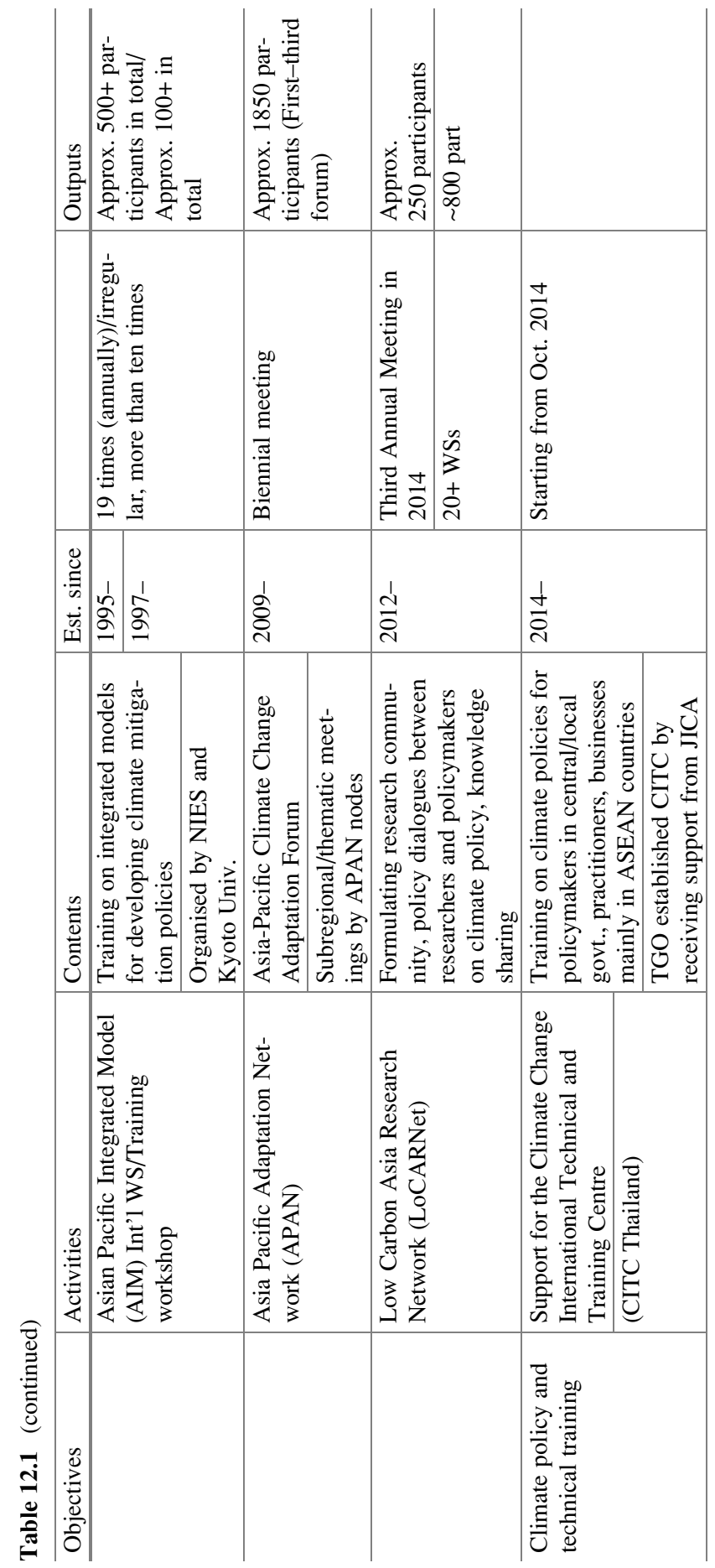


Group II. Following UNFCCC establishment, this seminar has focused not only on science and continues to function as a forum for knowledge exchange amongst Asia's climate change policymakers and related international organisations on responses to the UNFCCC. Meetings rotate within Asian nations and the 23rd was held in 2014.

A Permanent Research-Dedicated Institution to Lead Environmental Research in Asia Under a prime ministerial initiative after the 1992 Earth Summit in Rio de Janeiro, the Institute for Global Environmental Strategies (IGES) was established in 1998. IGES is an institute dedicated to conducting research on environmental issues in Asia. With a staff of about 200, including researchers from both within and outside Asia and management, it operates to maintain the various cooperative research networks and implement research activities that are mainly focused on Asia.

Sharing Scientific Bases for Policymaking As shown in Fig. 12.2, a substantial amount of scientific data and assessment methodologies are required for policymaking in response to climate change. Of such, accurate ascertainment of GHG emissions and inventory work are particularly important. In recognition of this - and of the importance of setting fundamental processes at an early stageGoJ, upon the request of the IPCC, established the Technical Support Unit (TSU) of the IPCC Task Force on National Greenhouse Gas Inventories at IGES in 1999. The IGES research units, in cooperation with the IPCC TSU and researchers from other Asian nations, led the task of amassing emission factors for Asia's unique forest soil and rice fields. In 2002, the Greenhouse Gas Inventory Office of Japan (GIO) was established in the National Institute for Environmental Studies (NIES). Using this office as a base, GoJ, in cooperation with IPCC TSU and the UNFCCC, launched the 'Workshop on Greenhouse Gas Inventories in Asia (WGIA)' in order to build capacity with the goal of ascertaining of GHG emissions throughout Asia. This workshop, which is hosted in a round-robin fashion by Asian countries, pairs up policymakers and researchers to form research communities that can maintain scientific accuracy over the long term. The latest data shared at the workshops is also reflected in national communications and policy formation in each country. The year 2014 marked the 13th year of this workshop, and since 2013, when BUR became obligatory, it has attracted over 120 delegates. These workshops have greatly contributed to estimating GHG emissions in Asia based on sharing of QA/QC methods and mutual learning.

Consistent Support for Policy Formulation Based on Integrated Assessment Models The application of integrated assessment models is indispensable in refining and coalescing the ideas of disparate ministries and agencies into consistent plans and policies for individual countries, including NAMAs and INDCs. The National Institute for Environmental Studies and Kyoto University began developing the Asia-Pacific Integrated Model (AIM) for climate policy in 1990, the goal of which is to promote its use in Asian countries, and joint research with China and India has taken place. Based on five years of research from 2004, this model is at 
present used in the drafting of Japan's plan for a low-carbon society. With the target of applying the model to ASEAN countries via 'Low Carbon Asia Research' from 2009, annual AIM Symposiums have been held jointly with researchers from each country to promote support for climate policy formation in each country. The model was applied to the creation of NAMA and INDC in Thailand and to the low-carbon city plan for Iskandar in Malaysia. In parallel with these activities, since 1994, 12 AIM training workshops (about 50 participants each) have been held, which are targeted at researchers and policymakers in Asia to foster development in climate policy at both the national and city levels.

Formation of a Research Community to Support Low-Carbon Development Policy in Each Country The Low Carbon Asia Research Network (LoCARNet: see Sect. 12.2 of this paper) forms a community for research on low-carbon societies with ownership by each respective country and aims to directly support policy in each country and to promote science-based low-carbon development policy throughout the region via mutual cooperation in the Asian region and South-South cooperation. The network was proposed at the ASEAN + 3 Environmental Ministers Meeting and has been active since 2012. Considering the urgent nature of climate policy, the network is led by researchers already deeply involved in policy support. Policy dialogue workshops between policymakers and research communities have been held in various countries. At the network's annual meetings, which began in 2012, discussions take place on key research topics for low-carbon development. At the annual meeting in Bogor in 2014, in the Bogor Declaration entitled 'Asia Is Ready to Stabilise Climate', researchers highlighted efforts towards climate stabilisation in Asia and also reported on the potential for reductions in Asia and good practices in Asia to provide input to international policymaking processes such as the UNFCCC. In order to become an independent leading network for low-carbon policy research in Asia, the formation of a $\mathrm{CoE}$ (centre of excellence) alliance is underway. The network aims to foster research communities in countries that currently lack them-Cambodia, Lao PDR and Myanmar-through South-South cooperation.

Funding for Climate Change Policy Research The Asia-Pacific Network for Global Change Research (APN) is a research fund that promotes not only research on climate change but also on the overall global environment, including biodiversity, transboundary air pollution and marine pollution. Activities were launched in 1996 on the initiative of Japan and with funds provided by the United States, Australia, New Zealand and the Republic of Korea. APN provides funding for joint research amongst Asian researchers. From 2013, the Low Carbon Initiatives (LCI) fund was established to accelerate low-carbon research in this region.

Knowledge Sharing on Climate Change Adaptation Upon the launch of the IPCC, Japan served as the Vice-Chairman of Working Group II (impact assessment) and was in charge of the chapter 'Technical Guidelines for Addressing Climate Change Impacts and Adaptations' of the Second Assessment Report in 1995. Utilising the Guidelines released in 1994, research on impacts and adaption was carried out in 
many developing countries. Japan also took the lead in the chapter on impacts and adaptation in Asia for the Third and Fourth reports by forming a research community for the same in the Asian region based on APN research funds.

As the impacts of climate change vary from place to place, adaptation measures suited to each respective setting are needed, and such measures can be bolstered through shared experience. This was the concept behind the Asia Pacific Adaptation Network (APAN), which was proposed by the Ministry of the Environment of Japan and established in 2009 by a Thai prime ministerial declaration. This network is a forum for knowledge sharing between researchers, policymakers and experts engaged in the field of adaptation measures in Asian nations, and its activities are overseen by a secretariat in Bangkok. The influence of APAN as a role model of good practice has extended to other regions of the world-the creation in 2013 of the Global Adaptation Network (GAN) by United Nations Environment Programme (UNEP) is one example.

Developing Human Resources for Low-Carbon Policy Formation Since the 1980s, the Ministry of the Environment of Japan, in cooperation with the Japan International Cooperation Agency (JICA), has focused its efforts on human resource development to support environmental research and policy in Asia. Results of such are the Environment Research and Training Centre (ERTC) created in Thailand in 1989, the Environmental Management Centre (EMC) in Indonesia in 1990 and the Sino-Japan Friendship Centre for Environmental Protection in 1990. Recognising the importance of Asia's response to climate change, JICA provided assistance for establishing the Climate Change International Technical and Training Centre (CITC) under Thailand's Ministry of Natural Resources and Environment (MONRE) and the Thailand Greenhouse Gas Management Organisation (TGO). This centre, which began operating in May 2014, conducts training for policymakers, experts and industry representatives from the ASEAN in the areas of GHG inventories, low-carbon societies, mitigation measures and technology and adaptation measures. Leading researchers from the ASEAN region of LoCARNet have advised on training content and participated in curriculum development and lectures. Both IGES and the LoCARNet have participated as JICA experts.

\subsection{The Low Carbon Asia Research Network (LoCARNet)}

\subsubsection{Science-Based Policy Formulation: LoCARNet Research and Policy Integration Activities}

In keeping with trends in international discussions, the countries of Asia continue to make steady progress in developing low-carbon plans and strategies based on a green economy. The Low Carbon Asia Research Network (LoCARNet; secretariat: 
IGES) supports development planning and strategy building by researchers and research institutes in various Asian countries in cooperation with the National Institute for Environmental Studies and Kyoto University. By setting up opportunities for researchers and policymakers to engage in discussion, each country can show how it is quantitatively reducing GHG and take planned actions to enable more effective policymaking for low-carbon development. Further, because countries in the region share a common economic footing and geographic location, researchers in each country can pool research results, carry out knowledge sharing and actively promote a system of mutual learning to facilitate South-South cooperation. Below is an overview of LoCARNet.

\subsubsection{Background, Sequence of Events, Organisation and Policies}

\section{Background and Policies}

LoCARNet is an open network of researchers, research organisations and likeminded relevant stakeholders that facilitates the formulation and implementation of science-based policies for low-carbon development in Asia.

A new international framework currently being considered by UNFCCC includes all GHG emitter countries from 2020 and beyond. In order to stabilise global climate, in addition to developed countries being required to drastically reduce their GHG emissions, those of developing countries will also need to be reduced based on their predicted increases. If trends in mass energy consumption and growth continue, by 2050 Asia will account for half of total global emissions, which will also cause heavy concomitant impact on the region's populations. On the other hand, if the substantial investments are redirected towards creating low-carbon societies, Asia could lead the world in low-carbon development. Right now, we are standing at the crossroads.

All countries in the Asian region are currently working on plans to achieve low-carbon development. Numerous policy steps are involved, and the formulation of such plans requires scientific knowledge spanning a broad spectrum of fields. It is thus plainly apparent that an interdisciplinary community for researchers and research organisations needs to be formed. Also, as policies for low-carbon development involve important decisions that determine a country's future potential, each country should have the right to self-determination in formulating these policies, therefore must have its own robust, scientific research footings.

While the above calls for establishing unique foundations, commonalities exist in the regional environment and in stages of development. In this regard, the exchange of scientific knowledge amongst researchers in Asian countries in respective areas of expertise will greatly promote science-based low-carbon policies, and reinforcing the scientific base to bolster the formulation of policies for low-carbon development in each country in the region will require a quantum leap in cooperation, not only from researchers and research communities but also 
from international organisations, donor agencies, NGOs and other like-minded relevant stakeholders. The ultimate aim of LoCARNet is to promote regional cooperation to facilitate the formulation and implementation of science-based policies for low-carbon growth in the Asian region, together with relevant stakeholders.

LoCARNet effectively promotes research on low-carbon growth policy by enabling effective dialogue between scientists and policymakers and also encourages domestic collaboration amongst researchers whose research capacities and scientific knowledge are firmly grounded in their home countries (ownership in country by these researchers). LoCARNet also aims to increase research capacity in the region through knowledge sharing and information exchange, in the context of not only North-South cooperation, but also South-South regional cooperation (Box 12.1).

\section{Box 12.1 Unique Characteristics of LoCARNet}

Unique characteristics of LoCARNet

- LoCARNet is a network of leading researchers, research organisations and like-minded relevant stakeholders deeply involved in low-carbon growth policy processes in Asia.

- Science-Science-Policy Dialogue: LoCARNet promotes research on policies for low-carbon growth by enabling sufficient dialogue between scientists and policymakers.

- Country-based ownership of knowledge: LoCARNet encourages collaboration between researchers in-country whose research capacity and scientific knowledge are firmly grounded on home soil.

- Regional South-South-North Collaboration: LoCARNet aims to increase research capacity in the AP region through knowledge sharing and information exchange as a part of regional cooperation—not only North-South but also South-South cooperation.

\section{Establishment of LoCARNet}

From 2009, Japan's Ministry of the Environment and National Institute for Environmental Studies embarked on a research programme on low-carbon development in Asia. Under this coalition, IGES, together with NIES and Kyoto University, has been conducting workshops that promote dialogue between policymakers and researchers in Indonesia, Thailand, Cambodia and Malaysia, as well as networking amongst researchers in the region to encourage low-carbon development in Asia. During the course of these workshops, it became clear that low-carbon development in Asia must take place. 
Considering the significance of Asia for global climate policy, the Government of Japan and IGES proposed the creation of LoCARNet at the October 2011 ASEAN + 3 Environmental Ministers' Meeting in Cambodia. The launch took place in April of the following year at a side event ('East Asia Low Carbon Development Knowledge Partnership', organised by three institutes-National Institute for Environmental Studies, Japan International Cooperation Agency (JICA) and IGES) one day prior to Japan's Ministry of Foreign Affairs' 'East Asia Low Carbon Growth Partnership Dialogue'. It was then officially reported to the Dialogue the following day. As IGES had been commissioned to organise the Secretariat of the International Research Network for Low Carbon Societies (LCS-RNet) based on a decision made at the G8 summit in 2008, it was also tentatively placed in charge of the Secretariat function of LoCARNet as well.

Recent trends point to initiatives in low-carbon, green growth taking place in many parts of the region, and such are supported by developed countries and international organisations. Concurrently, LoCARNet will facilitate the creation and accumulation of knowledge to help formulate and implement science-based policies for low-carbon growth in the Asia region.

\section{Scope of Activities}

The knowledge required and the issues related to promoting low-carbon growth policies are extremely diverse in nature. As such, the network needs to focus its sphere of activities on priority areas in order to provide efficient and effective results.

Regionally: ASEAN Core, Centred on Asia, Futuristically Global Although the significance of Asia was previously mentioned, China has already established a strong low-carbon policymaking process for itself and also leads the world in utilisation of renewable energies, both in terms of facilities and production. As regards India, its per capita GHG emissions are still low although it has the potential to become an emission giant in the future. Therefore, for the time being, the network will primarily focus on the parts of the ASEAN region that are undergoing striking development, with initiatives in this region making up its core activities. The network will, however, continue to promote research exchange that includes China and India.

Since the Copenhagen Accord, cooperation between developed and developing countries has intensified. In response to this, comparatively recently, momentum has been building for knowledge sharing around the world: initiatives similar to LoCARNet have been initiated by Europe, the United States and international organisations. In addition, LCS-RNet, promoted by Japan with the G8 countries, intends to expand its network to include emerging economies and developing countries, where GHG emissions are predicted to increase greatly in the future, while collaborating with LoCARNet in Asia. Further, as LCS-RNet has been requested to deal with integration of mitigation and adaptation, it is thought that 
LoCARNet will assist in maximising collaboration in these initiatives to yield mutually beneficial and effective results.

Targets: Low-Carbon Research as the Core, Stronger Links with Policy and Industry The objective of the network is to further low-carbon development. To do so, it is necessary to promote scientific policy based on research. Hence, it is essential to first have a robust research community in each country. However, these communities are meaningful only when research is reflected in policy and industrial activities, making strong cooperation with government (both central and local government) and business sectors a must.

Stakeholders: Researchers at the Core, Cooperation with Policymakers and Participation of Supporters, Expansion of Related Parties The roots of the network will be grounded in its research capacity. The skills of researchers involved in low-carbon development must be consolidated and the research community expanded; as such, researchers will play the leading role. Deliberation on issues to be addressed must be made from the viewpoint not only of scholarly but also policy aspects. Also, support from policymakers and the role of funding agencies are substantial in terms of finance and organisational aspects. In order to disseminate outcomes and bring about impacts, the cooperation of a broad range of stakeholders, including international organisations and NGOs, is essential.

\subsubsection{Activities and Outcomes}

The activities of LoCARNet can be categorised under three pillars. Here again, the countries of Asia continue to make steady progress in developing low-carbon plans and strategies based on a green economy.

As the first pillar, LoCARNet has maintained policy dialogue between researchers and policymakers in selected countries, together with the National Institute for Environmental Studies and Kyoto University. For example, LoCARNet experts in Indonesia, working with the National Development Planning Board (BAPPENAS), have conducted an economic evaluation comparison of a low-carbon development draft plan; a LoCARNet expert in Thailand has worked closely with the Thailand Greenhouse Gas Management Organization (TGO) and reflected his analysis within Thailand NAMA development, and in Iskandar, Malaysia, a LoCARNet expert has been conducting low-carbon city planning and implementation in order to promote collaboration with local universities and implementing organisations.

Through these policy dialogue sessions, policymakers have gradually recognised the importance of in-country involvement of researchers and research communities in the policymaking process, and as a consequence, scientific policymaking has been promoted in these countries.

In parallel, as a result of bolstered human resources in Japan (National Institute for Environmental Studies (NIES), Kyoto University and IGES) engaged in 
supporting low-carbon development in developing countries, a series of steps has been established for low-carbon development planning, including development of the GHG inventory, vision development, quantitative scenario creation, economic evaluation, action plan design and road map formulation.

As the second pillar, having conducted several workshops for capacity development in Cambodia, LoCARNet organised a trilateral workshop for Cambodia, Lao PDR and Myanmar in February 2014 in Phnom Penh, Cambodia. This workshop aimed to have Cambodia, Lao PDR and Myanmar each utilising its own capacity to present quantitative GHG emission reduction potentials, to advance the organisation of research communities in-country, to enhance policymaking in a more effective manner and to provide a forum for researchers and policymakers to engage in discussion. In addition, owing to the various commonalities shared by the participating countries, including level of economic development and geographical characteristics, this workshop also provided opportunities for researchers in each country to bring together their research results, carry out knowledge sharing and actively promote a system of mutual learning that facilitates South-South cooperation. Through such activities, countries such as Cambodia, Lao PDR and Myanmar are projected to be in a better position to implement the low-carbon plans discussed in the workshop.

As the third pillar, LoCARNet organised a series of annual meetings- the first being in October 2012 in Bangkok (Thailand), second in July 2013 in Yokohama (Japan) and third in October 2014 in Bogor (Indonesia). These meetings underscored the importance of networks as fora for sharing knowledge in order to bring about low-carbon societies and low-carbon development. Further, a number of urgent issues for research common to the Asian region were discussed, including 'the need for capacity development towards the framework for 2020', 'comparison of reduction potential of Asian countries towards achieving the two degree target', 'the role of cities as pioneers for LCS', 'low-carbon technologies required in Asia', 'Asian issues: emission reduction in the agriculture, forestry and land-use sectors' and 'integration of low-carbon issues and climate change adaptation'. It is likely that LoCARNet will transfer these outputs from the research community to the policy training centres planned for ASEAN countries (Thailand and Indonesia).

In addition, knowledge sharing at the annual meetings and South-South regional cooperation together increase momentum towards realising low-carbon development in Asia, which could realise a significant GHG reduction potential and sends a very positive message. In November 2014, LoCARNet organised its Third Annual Meeting, held in Bogor, Indonesia, where researchers in Asia issued the 'LoCARNet Bogor Declaration', which states 'Asia is ready to stabilise climate' (Box 12.2). 


\section{Box 12.2 LoCARNet Bogor Declaration (November 2014)}

\section{LoCARNet Bogor Declaration}

\section{Asia Is Ready to Stabilise Climate}

Recognising the huge risk of climate change to human well-being as predicted by science communities; welcoming the start of a new global regime to avert it; confirming the growing importance of regional cooperation for low-carbon transition; and drawing upon Asian wisdom to contribute in stabilising climate, the participants of the LoCARNet Third Annual Meeting reaffirm that:

1. Asia has research capacity; Asia has research networks that support policymaking.

2. Asia has the potential for low-carbon transition which is adequate to contribute to the two degrees temperature stabilisation target.

3. Asia has the technological, financial and institutional capacity to facilitate low-carbon actions.

4. Many 'good practice' examples exist and their replication is challenging. Continued technological and institutional innovations are needed to support the transition to a sustainable low-carbon society.

5. Asia is ready to make due contribution to global climate stabilisation.

However:

1. Diversity amongst Asian nations poses challenges for framing uniform policies, but provides opportunities for discovering a range of options. Regional cooperation for low-carbon research is therefore challenging as well as rewarding.

2. Asia houses a sizable fraction of low-income families. Their development needs require special attention to ensure that their welfare is not compromised.

Low-carbon research in Asia shows that timing is critical; lock-ins must be avoided, and all 'leapfrogging opportunities' should be seized and realised by positive actions, supported by global climate policies, including technology transfer and incremental finance.

Asia is ready for low-carbon transition and awaits signals from the Paris Climate Change Agreement to deploy actions towards climate stabilisation.

26 November 2014

Low Carbon Asia Research Network (LoCARNet)

\subsubsection{Future Plan}

Three years have passed since LoCARNet's official launch. During this time, research institutes and organisations in Asia have exhibited considerable development, and based on cooperation activities conducted so far, now is time for Asia to 
mobilise the necessary knowledge through its own capacity and to establish and manage an autonomous, regionally owned network.

Under the new post-2015 framework, respective governments in Asia should promptly develop long-term, low-carbon development plans and put them in effect. In order for Asia to develop its own policies with full ownership, the region must possess an autonomous regional research community. And, at the policy implementation stage, it is necessary for science (research) to be reflected in policies. Moreover, knowledge held in the scientific community must be leveraged to make relevant stakeholders, especially in business, and move towards low-carbon development. Under the LoCARNet scheme, several research institutes and organisations exist in this region, which are already working closely with policymakers and involved in the policymaking process in their respective specialised fields as centres of excellence $(\mathrm{CoE})$. However, in the future, synergy effects amongst these institutes, as a $\mathrm{CoE}$ coalition or $\mathrm{CoE}$ alliance, must be maximised to drive progress in policies and in the business sector in this region.

In this transitional stage that includes 2015, it will be imperative to make policy proposals, in parallel, to each government, to the Asian region, to the global international community and to relevant stakeholders. This project will take the form of action research that develops the organisation through these kinds of onthe-job activities.

As regards future network activities, LoCARNet will focus on promoting priority research in fields common to the Asian region; facilitating financial and institutional support for fostering and strengthening research capacity in the region, in collaboration with donors, other institutions and organisations concerned; securing routes to reflect research results in policymaking; and activating networking and information dissemination with and to other like-minded stakeholders towards realising low-carbon societies and low-carbon development.

Open Access This chapter is distributed under the terms of the Creative Commons Attribution Noncommercial License, which permits any noncommercial use, distribution, and reproduction in any medium, provided the original author(s) and source are credited.

\section{References}

IPCC (2013) Summary for policymakers. In climate change 2013: the physical science basis, p 28 IPCC (2014) Summary for policymakers. Working group III: Mitigation of climate change, p 11 Nishioka S (1990) Policy scientific insight required for responding to global warming. Environ Res Q 77:14-20 (in Japanese) 